\title{
Prevalence Of Lichen Planus And Leukoplakia - A Hospital Based Study
}

Research Article

Preetha Parthasarathy ${ }^{1}$, Maragathavalli . $\mathrm{G}^{2 *}$, Sreedevi Dharman ${ }^{3}$

${ }^{1}$ Saveetha Dental College and Hospitals, Saveetha Institute of Medical and Technical Sciences, Saveetha University, Chennai, India.

${ }^{2}$ Professor \& Head, Department of Oral Medicine and Radiology, Saveetha Dental College and Hospitals, Saveetha Institute of Medical and Technical Sciences, Saveetha University, Chennai, 600077, India.

${ }^{3}$ Reader, Department of Oral Medicine and Radiology, Saveetha Dental College and Hospitals, Saveetha Institute of Medical and Technical Sciences, Saveetha University, Chennai, 600077, India.

\section{Abstract}

Lichen planus is a chronic immune mediated disorder affecting the oral and dermal parts of the body. Oral leukoplakia is a white plaque of questionable risk that carries risk for malignant transformation. The study was carried out in order to find correlation between the clinical variants with age and gender of patients with lichen planus and leukoplakia. The aim of this study is to evaluate the prevalence of lichen planus and leukoplakia among patients visiting the hospital.The study was conducted in a University set up in a Private dental College, Chennai. The study was a retrospective study with a sample size of 142 . The data was collected from the hospital digital database by reviewing and analysing the case sheets of patients who visited the hospital between June 2019 to March 2020. The collected data was entered in an excel sheet and was tabulated using SPSS software version 19. Chi-square test was performed.It was observed that both the type, erosive type of lichen planus and the reticular type was prevalent in the female population $(36.17 \%$ \& $27.66 \%$ respectively). Erosive type of lichen planus was common at the age group 46-60years $(36.17 \%)$ and the reticular type was common at the age group 20-45 years $(21.28 \%)$. Homogeneous and non homogeneous type of leukoplakia both were more prevalent among the male population $-73.68 \%$ and $21.05 \%$ respectively ( $\mathrm{P}$ value was found to be statistically significant- 0.004). The age group 41-60 years were the commonly affected group by both the variants of leukoplakia. Within the limits of the study, it was observed that both the variants of lichen planus, erosive type and reticular type were prevalent among the female population. Erosive type of lichen planus was common at the age group 46-60 years and reticular type of lichen planus at the age 20-45 years. Homogeneous and non-homogeneous types of leukoplakia, both were prevalent in male population with 40-60 years of age being the commonly affected group.

Keywords: Lichen Planus; Leukoplakia; Erosive; Reticular; Homogenous.

\section{Introduction}

Oral lichen planus is an immune mediated potentially malignant disorder. It is characterised by the presence of vesicles and bullae. It frequently affects the female gender more than the male gender. It is usually present in the fourth decade of life [1]. Clinically like in planus is represented by various types which are reticular, erosive, papular, atrophic, plaque-like and bullous type $[2,3]$.

Intraorally, buccal mucosa, tongue and gingiva are the commonly involved sites [4]. It can either present alone or with concomitant skin lesions [5]. The clinical features of lichen planus are bilateral or multilateral lesions with Wickham's striae with raised papules, erosions, atrophic lesions that manifest at intraoral sites [6, 7]. It has been reported that patients with oral and skin lesions are associated with diabetes mellitus. Grinspan syndrome is a triad which involves lichen planus, diabetes mellitus and hypertension $[8,9]$. The malignant transformation rate of lichen planus has been found to be 0.5 to $2 \%$.

Leukoplakia is a white patch or plaque of questionable risk having excluded other known diseases that carry no increased risk for cancer [10]. It is a common type of lesion that affects 0.2 to $4.9 \%$ of the world population [11]. Clinically leukoplakia is subdi-

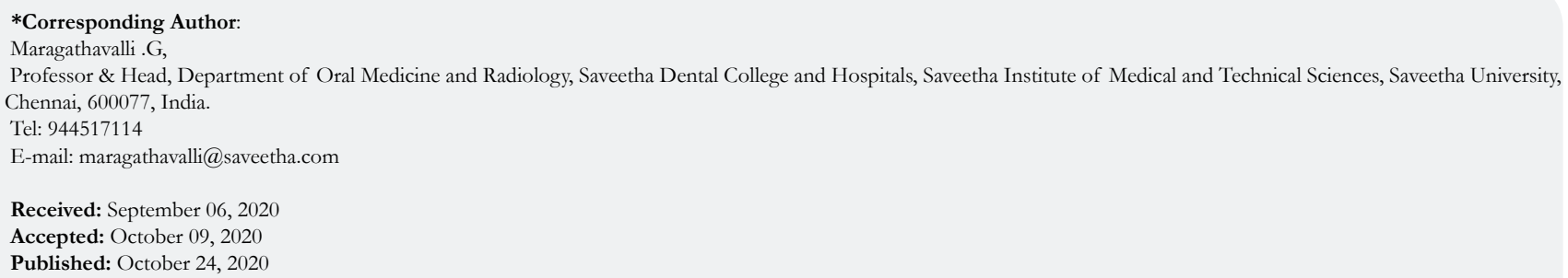

Copyright: Maragathavalli .G ${ }^{\odot} 2020$. This is an open-access article distributed under the terms of the Creative Commons Attribution License, which permits unrestricted use, distribution and reproduction in any medium, provided the original author and source are credited. 
vided into homogeneous and non-homogeneous types. The homogeneous type, the lesion appears to have a white flat or slightly wrinkled surface. The non-homogeneous type is represented with speckled or nodular surfaces [12]. Histopathologically, leukoplakia represents hyperkeratosis with or without epithelial dysplasia [12].

The common aetiology for leukoplakia includes tobacco consumption in the form of chewing or smoking. Apart from that, sharp teeth Iron deficiency, dislodged dental restorations can also cause leukoplakia. The non-homogeneous type of leukoplakia has a greater risk of malignant transformation than the homogeneous leukoplakia. The malignant transformation rate of leukoplakia ranges from 0.13 to $17.5 \%[13,14]$. According to Arvind $\mathrm{M}$ et al, smokeless tobacco predisposes to an increased risk of PMD and oral cancer development [15].

Recent studies have focussed on Tobacco consumption and its effect on oral tissues. It is available in two forms: smoked and smokeless. The smoked form of tobacco contains carbon monoxide, thiocyanate, hydrogen, cyanide, nicotine and the metabolites of these constituents, on the other hand smokeless tobacco contains nitrosamine, polycyclic aromatic hydrocarbons and nitrosoproline. The smoked form of tobacco is available in various forms such as bidi, chilum and cigarette whereas the smokeless tobacco is available in the forms of dry snuff, moist snuff, khaini quid (tobacco + slaked lime). The chemical constituents of tobacco and its combustion end products as tars and resins are irritating substances capable of causing leukoplakia. Over 300 carcinogens have been identified in tobacco smoke [16].

Few studies suggest that levels of MMP-9 in potentially malignant disorders such as OSMF, leukoplakia, lichen planus, has shown an elevation [17]. T N Uma et al, in their study has discussed the non invasive salivary markers like Micro RNA in detection of oral potentially malignant disorder [18].

Previously our team had conducted numerous clinical trials 19, [20-27], few questionnaire study and review papers [28-30] over the past 5 years. Now we are focussing on retrospective studies. The idea for the present study was obtained from the current interest in our community.

The purpose of the present study is to evaluate the type of variants in lichen planus and leukoplakia and their prevalence in the general population to help in clinical diagnosis and in dental practice.

\section{Materials and Methods}

The study was conducted in a Private dental College Chennai which is a University set up. The population chosen for the study included patients with leukoplakia and lichen planus. The data was collected from the hospital digital database by reviewing and analysing over 86000 case sheets between June 2019 to March 2020. Two examiners were included in the study.

The study was conducted retrospectively. Cross verification of data for error was done by presence of additional reviewers and by photographic evaluation. Simple random sampling was done to minimize sampling bias. After reviewing, the case sheets were filtered based on data required. The final sample size was 142, among which 95 patients had leukoplakia and 47 patients had lichen planus. The inclusion criteria was all patients with leukoplakia and lichen planus. The exclusion criteria was insufficient or unavailable data on lichen planus and leukoplakia, incomplete case sheets, patients without any premalignant disorders.

\section{Data collection}

The collected data was based on patients having leukoplakia and lichen planus. The individual clinical variants of each patient were also collected.

\section{Statistical analysis}

The collected data was entered in an excel sheet and tabulated. It was then imported to SPSS software version 19. Descriptive statistics was used to correlate between the type of lesion and its clinical variants with age and gender. The dependent variable was patients with lichen planus and leukoplakia and the independent variable was age, gender and clinical variants. Chi square test was performed and the level of significance was set at 0.05 .

\section{Ethical approval}

The ethical approval for the retrospective study was obtained from the Institutional scientific review board.

\section{Results and Discussion}

The collected data was imported in SPSS software version 19 and the results were obtained using chi-square test. It was observed that the erosive type of lichen planus was more prevalent in females $(36.17 \%$ ) and in males it was $23.40 \%$. The reticular type of lichen planus was more prevalent in females which had an incidence of $27.66 \%$ and in males $12.77 \%$. (Figure 1). The $\mathrm{P}$ value was not found to be statistically significant $(>0.05)$. Age and clinical variants of lichen planus were assessed. It was found that patients of the age group 46-60years had more prevalence of erosive type of lichen planus and patients of the age group 20-45 years had prevalence for reticular type of lichen planus (Figure 2) for which the $\mathrm{P}$ value was not found to be statistically significant $(>0.05)$. Comparing the gender with clinical variants of leukoplakia, it was observed that, both the types, homogeneous and nonhomogeneous were prevalent in male population $(73.68 \%$ and $21.05 \%$ respectively) (Figure 3 ). The $\mathrm{P}$ value was found to be statistically significant 0.004 . Age and clinical variants of leukoplakia was assessed; it was observed that the homogeneous type of leukoplakia was more prevalent at the age group 41-60 years $(36.84 \%)$ and the non-homogeneous type was more prevalent at age group 41-60 years (18.95\%) for which the $\mathrm{P}$ value was not found to be statistically significant $(>0.05)$ (Figure 4$)$.

From the study it was observed that both the type, erosive type of lichen planus and the reticular type was prevalent in the female population $(36.17 \% \& 27.66 \%$ respectively). Erosive type of lichen planus was common at the age group 46-60years $(36.17 \%)$ and the reticular type was common at the age group 20-45 years (21.28\%). Homogeneous and non homogeneous type of leukoplakia both were more prevalent among the male population $73.68 \%$ and $21.05 \%$ respectively. The age group $41-60$ years were the commonly affected group by both the variants of leukoplakia. 
Figure 1. Bar graph showing association between gender and clinical variants of lichen planus The $\mathrm{X}$ axis denotes the gender of the patients and $\mathrm{Y}$ axis denotes number of patients with lichen planus. It is observed that females have more prevalence for both, erosive and reticular variants (blue and green respectively). The $P$ value was 0.589 which is $>0.05$ thus, showing there is no significant association between gender and clinical variants of lichen planus.

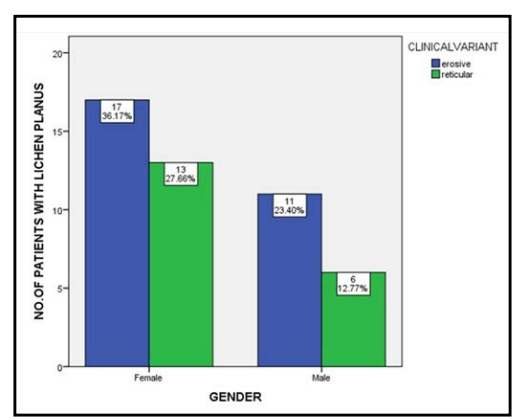

Figure 2. Bar graph showing association between age and clinical variants of lichen planus. The $\mathrm{X}$ axis denotes the age of the patients and $\mathrm{Y}$ axis denotes the number of patients with lichen planus. The age group of 46-60years had more prevalence of erosive type (blue) whereas reticular type (green) was more prevalent in the age group 20-45years. The $P$ value was 0.136 which is $>0.05$, thus showing there is no significant association between age and clinical variants of lichen planus.

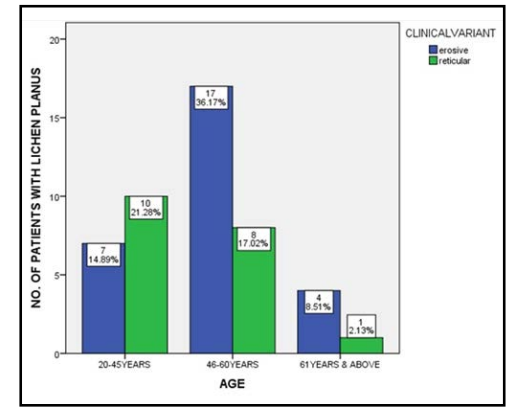

Figure 3. Bar graph showing association between gender and clinical variants of leukoplakia. The $\mathrm{X}$ axis denotes the gender of the patients and $\mathrm{Y}$ axis denotes number of patients with leukoplakia. It is evident that both homogeneous and nonhomogenous types of leukoplakia are prevalent in male population (blue and green respectively). The $\mathbf{P}$ value was 0.004

which is $<0.05$ thus showing there is significant association between gender and clinical variants of leukoplakia.

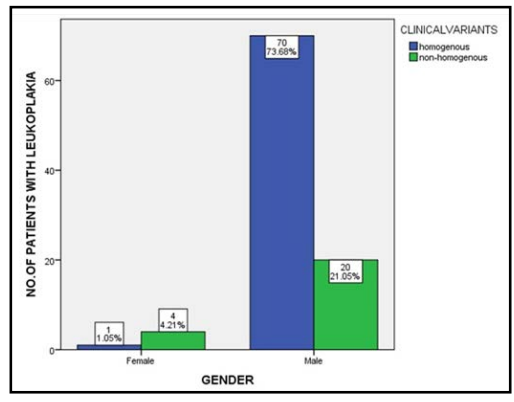

Figure 4. Bar graph showing association between age and clinical variants of leukoplakia. The $\mathrm{X}$ axis denotes age of the patients and $\mathrm{Y}$ axis denotes number of patients with leukoplakia. The non-homogeneous (green) type and homogenous type (blue), both the variants, were prevalent in the age group 41-60 years. The $P$ value was 0.089 which is $>0.05$ thus showing there is no significant association between the age and clinical variants of leukoplakia.

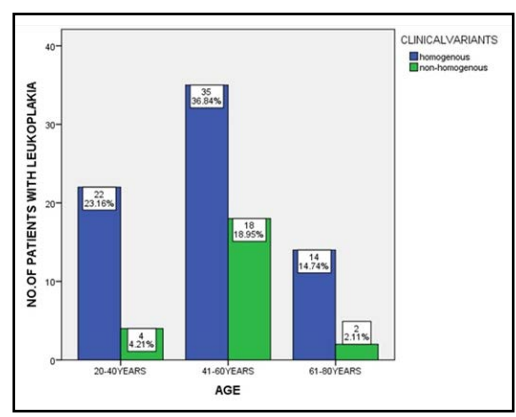


Mostafa et al, in their study has observed that, the female patients had more prevalence for lichen planus (68.7\%) and commonly occured at the fourth and sixth decade of life with a erosive type being the common finding [31], this study is in accordance with the current study.

Sachdev R et al, In the study has stated that, the lichen planus was prevalent in male population $(75.4 \%)$ and occurred in the 4 th to 6 decade of life $(62.2 \%)$ and found the reticular type of lichen planus was more prevalent $(67.6 \%)$ which is followed by the erosive type- $26.4 \%$ [32], this study is in contrast to our study which shows a female predominance for lichen planus.

From Jasmine et al study, it is observed that the male had more prevalence for lichen planus and the mean age group was 38.5 years [1]. This study shows a contrast to the current study as the current study represents a prevalence for the female population in lichen planus.

Brouns et al, has found that the homogeneous type and of leukoplakia was more prevalent in the male population [33]. This study is in accordance with the current study. Boker et al, has observed that $2.2 \%$ prevalence of leukoplakia in a smaller population and the age group in which leukoplakia occurred was 40 to 50 years with a male predilection [34]. This study is in accordance with the present study, as our study also shows a male predilection for leukoplakia. Liu et al, in their study, has discussed that the peak incidence of the disease was the fifth decade of life- 33\% [35]. This is in par with our study.

Jaya Gopal R et al has found that leukoplakia was more prevalent at age group 70 to 99 years $(13.04 \%$ ) followed by 50 to 69 years $(10.2 \%)$ and also found male predominance for leukoplakia [36]. This study is in accordance with our study which also shows a male predominance with the commonly affected age group being 41-60 years.

The present study is in accordance with the previous literature and can be used as a guide in clinical practice and diagnosis. Though the study shows statistical significance, the limitations in the study include smaller sample size and geographical variations. Thus, future studies should be done with a larger sample size and equal distribution of study parameters for a better view on the point of study.

\section{Conclusion}

Within the limits of the study, it was observed that both the variants of lichen planus, erosive type and reticular type were prevalent among the female population. Erosive type of lichen planus was common at the age group 46-60 years and reticular type of lichen planus at the age 20-45 years. Homogeneous and nonhomogeneous types of leukoplakia, both were prevalent in male population with 40-60 years of age being the commonly affected group. Thus, the study can be used as a reference in clinical practice and diagnosis.

\section{Acknowledgement}

The study was supported by the Institution who provided the in- sights and expertise that greatly assisted the study. We would also like to thank the reviewers of the articles for these insights.

\section{References}

[1]. Singh J, Singh S. Evaluation of prevalence of oral lichen planus in a known population: A cross-sectional study.2018.

[2]. Rojo-Moreno J, Bagán J, Rojo-Moreno J, Donat JS, Milián MA, Jiménez Y. Psychologic factors and oral lichen planus [Internet]. Vol. 86, Oral Surg Oral Med Oral Pathol Oral Radiol Endod. 1998. p. 687-91.

[3]. McCartan BE. Psychological factors associated with oral lichen planus. J Oral Pathol Med. 1995 Jul;24(6):273-5.

[4]. Cutler TP. Lichen planus caused by pyrimethamine. Clin Exp Dermatol. 1980 Jun;5(2):253-6.Pubmed PMID: 6449324

[5]. Hawk JL. Lichenoid drug eruption induced by propanolol. Clin Exp Dermatol. 1980 Mar;5(1):93-6.Pubmed PMID: 7398132

[6]. Munde AD, Karle RR, Wankhede PK, Shaikh SS, Kulkurni M. Demographic and clinical profile of oral lichen planus: A retrospective study. Contemp Clin Dent. 2013 Apr;4(2):181-5.Pubmed PMID: 24015006.

[7]. Bermejo-Fenoll A, Sánchez-Siles M, López-Jornet P, Camacho-Alonso F, Salazar-Sánchez N. A retrospective clinicopathological study of 550 patients with oral lichen planus in south-eastern Spain. J Oral Pathol Med. 2010 Jul;39(6):491-6.Pubmed PMID: 20456611.

[8]. American Diabetes Association. Diagnosis and classification of diabetes mellitus. Diabetes care. 2014 Jan 1;37(Supplement 1):S81-90.

[9]. Goyal L, Gupta ND, Gupta N. Grinspan syndrome with periodontitis: Coincidence or correlation?. J Indian Soc Periodontol. 2018 May;22(3):263.

[10]. Warnakulasuriya S, Johnson NW, Van der Waal I. Nomenclature and classification of potentially malignant disorders of the oral mucosa. J Oral Pathol Med. 2007 Nov;36(10):575-80.

[11]. Van der Waal I, Schepman KP, Van der Meij EH, Smeele LE. Oral leukoplakia: a clinicopathological review. Oral Oncol. 1997 Sep 1;33(5):291-301.

[12]. Carrard VC, van der Waal I. A clinical diagnosis of oral leukoplakia; A guide for dentists. Med Oral Patol Oral Cir Bucal. 2018 Jan 1;23(1):e59-e64.Pubmed PMID: 29274164.

[13]. Jr SS, Gorsky M, Ms FL. Oral leukoplakia and malignant transformation. A follow-up study of 257 patients. Cancer. $1984 \mathrm{Feb}$ 1;53(3):563-8.

[14]. Silverman S, Bhargava K, Smith LW, Malaowalla AM. Malignant transformation and natural history of oral leukoplakia in 57,518 industrial workers of Gujarat, India. Cancer. 1976 Oct;38(4):1790-5.Pubmed PMID: 1033027.

[15]. Muthukrishnan A, Warnakulasuriya S. Oral health consequences of smokeless tobacco use. Indian J Med Res. 2018 Jul;148(1):35.

[16]. Glick M. Burket's Oral Medicine, 12th Edition. PMPH USA; 2015. 732 p.

[17]. Venugopal A, Uma Maheswari TN. Expression of matrix metalloproteinase-9 in oral potentially malignant disorders: A systematic review. J Oral Maxillofac Pathol. 2016 Sep-Dec;20(3):474-479.Pubmed PMID: 27721614.

[18]. Maheswari TNU, Venugopal A, Sureshbabu NM, Ramani P. Salivary micro RNA as a potential biomarker in oral potentially malignant disorders: A systematic review. Ci Ji Yi Xue Za Zhi. 2018 Apr-Jun;30(2):55-60.Pubmed PMID: 29875583.

[19]. Chaitanya NC, Muthukrishnan A, Babu DBG, Kumari CS, Lakshmi MA, Palat G, et al. Role of Vitamin E and Vitamin A in Oral Mucositis Induced by Cancer Chemo/Radiotherapy- A Meta-analysis. J Clin Diagn Res. 2017 May;11(5):ZE06-ZE09.Pubmed PMID: 28658926.

[20]. Chaitanya NC, Muthukrishnan A, Krishnaprasad CMS, Sanjuprasanna G, Pillay P, Mounika B. An Insight and Update on the Analgesic Properties of Vitamin C. J Pharm Bioallied Sci. 2018 Jul-Sep;10(3):119-125.Pubmed PMID: 30237682.

[21]. Misra SR, Shankar YU, Rastogi V, Maragathavalli G. Metastatic hepatocellular carcinoma in the maxilla and mandible, an extremely rare presentation. Contemp Clin Dent. 2015 Mar;6(Suppl 1):S117-21.Pubmed PMID: 25821363.

[22]. Muthukrishnan A, Bijai Kumar L, Ramalingam G. Medication-related osteonecrosis of the jaw: a dentist's nightmare. BMJ Case Rep. 2016 Apr 6;2016:bcr2016214626.Pubmed PMID: 27053542.

[23]. Muthukrishnan A, Bijai Kumar L. Actinic cheilosis: early intervention prevents malignant transformation. BMJ Case Rep. 2017 Mar 20;2017:bcr2016218654.Pubmed PMID: 28320702.

[24]. Rohini S, Kumar VJ. Incidence of dental caries and pericoronitis associated with impacted mandibular third molar-A radiographic study. Res J Pharm Technol. 2017;10(4):1081-4.

[25]. Dharman S, Muthukrishnan A. Oral mucous membrane pemphigoid - Two case reports with varied clinical presentation. J Indian Soc Periodontol. 2016 Nov-Dec;20(6):630-634.Pubmed PMID: 29238145. 
[26]. Subha M, Arvind M. Role of magnetic resonance imaging in evaluation of trigeminal neuralgia with its anatomical correlation. Biomed. Pharmacol. J. 2019 Mar 25;12(1):289-96.

[27]. Choudhury P, Panigrahi RG, Maragathavalli, Panigrahi A, Patra PC. Vanishing roots: first case report of idiopathic multiple cervico-apical external root resorption. J Clin Diagn Res. 2015 Mar;9(3):ZD17-9.Pubmed PMID: 25954713

[28]. Subashri A, Maheshwari TN. Knowledge and attitude of oral hygiene practice among dental students. Res J Pharm Technol. 2016;9(11):1840-2.

[29]. Steele JC, Clark HJ, Hong CH, Jurge S, Muthukrishnan A, Kerr AR, et al. World Workshop on Oral Medicine VI: an international validation study of clinical competencies for advanced training in oral medicine. Oral Surg Oral Med Oral Pathol Oral Radiol. 2015 Aug;120(2):143-51.e7.Pubmed PMID: 25861956.

[30]. Patil SR, Maragathavalli G, Araki K, Al-Zoubi IA, Sghaireen MG, Gudipaneni RK, et al. Three-rooted mandibular first molars in a Saudi Arabian population: a CBCT study. Pesqui. Bras. Odontopediatria Clín. Integr. 2018 Aug 27;18(1):4133.

[31]. Mostafa B, Ahmed E. Prevalence of oral lichen planus among a sample of the Egyptian population. J Clin Exp Dent. 2015 Feb 1;7(1):e7-e12.Pubmed PMID: 25810846.

[32]. Sachdev R, Garg K, Mukherjee S. Reticular Lichen planus in young female: Rare case study.Dent Res J. 2019;1: 22-5.

[33]. Brouns ER, Baart JA, Bloemena E, Karagozoglu H, van der Waal I. The relevance of uniform reporting in oral leukoplakia: definition, certainty factor and staging based on experience with 275 patients. Med Oral Patol Oral Cir Bucal. 2013 Jan 1;18(1):e19-26.Pubmed PMID: 23085711.

[34]. Bokor-Bratić M. Prevalence of oral leukoplakia. Med Pregl. 2003;56(1112):552-5.

[35]. Liu W, Wang YF, Zhou HW, Shi P, Zhou ZT, Tang GY. Malignant transformation of oral leukoplakia: a retrospective cohort study of 218 Chinese patients. BMC Cancer. 2010 Dec 16;10:685.Pubmed PMID: 21159209.

[36]. Ray JG, Ganguly M, Rao BS, Mukherjee S, Mahato B, Chaudhuri K. Clinico-epidemiological profile of oral potentially malignant and malignant conditions among areca nut, tobacco and alcohol users in Eastern India: A hospital based study. J Oral Maxillofac Pathol. 2013 Jan;17(1):45-50.Pubmed PMID: 23798829. 